\title{
ESTUDO QUANTITATIVO DA PERCEPÇÃO DA QUALIDADE DE VIDA NO TRABALHO NA VISÃO DOS PROFESSORES DO CURSO DE ADMINISTRAÇÃO DA UNESC.
}

\author{
Rosane Deoclésia Aléssio Dal Toé \\ SENAI/SC - Florianópolis, rosane.toe@sc.senai.br \\ João Henrique Savaris \\ João Henrique Savaris - UNESC - <rda@unesc.net> \\ Roberto Dagostin \\ Roberto Dagostin - ENGEPLUS - <betodag@engeplus.com.br>
}

\begin{abstract}
RESUMO: O mundo do trabalho vem passando por transformações que afetam os colaboradores e a sociedade, inclusive os professores universitários. Neste sentido, o tema qualidade de vida no trabalho vem conquistando relevância no cenário social, pois engloba as expectativas, estilos e projetos de vida das pessoas e da coletividade, quando envolvem seu ambiente de trabalho. Sendo assim, realizou-se esta pesquisa, que teve como objetivo caracterizar e analisar os aspectos do estilo e da qualidade de vida de professores do ensino superior, especificamente no Curso de Administração da UNESC. O método de investigação empreendido foi de natureza quantitativa de cunho bibliográfico. Foram acessados artigos científicos, dissertações de mestrado e teses de doutorado, publicados nos bancos de dados informatizados. Buscou-se, também, literaturas no acervo da biblioteca da Universidade do Extremo Sul Catarinense - UNESC. O estudo foi classificado como de campo, exploratório e descritivo, sendo desenvolvido através de procedimentos quantitativos de coleta e análise dos dados, por meio de um questionário composto por 15 questões fechadas. Os participantes foram os professores do curso em estudo, totalizando 41 pesquisados, dos quais, 38 responderam o questionário, perfazendo $93 \%$ da amostra. Os resultados apontaram que os professores percebem a qualidade de vida no trabalho de forma positiva, estão satisfeitos com o ambiente de trabalho, e confiam na instituição a qual estão vinculados.
\end{abstract}

Palavras-chave: Instituições de Ensino. Docentes do Ensino Superior. Qualidade de vida no trabalho. Síndrome de Burnout. 


\section{INTRODUÇÃO}

O referido estudo tem como finalidade, pesquisar a visão dos professores do Curso de Administração da UNESC sobre a sua qualidade de vida no trabalho. Para isso, conforme a Organização Mundial da Saúde, a Qualidade de vida no trabalho, reflete a percepção dos indivíduos de que suas necessidades estão sendo satisfeitas ou, ainda, que lhes estão sendo negadas oportunidades de alcançar a felicidade e a auto-realização, com independência de seu estado físico de saúde ou das condições sociais e econômicas (OMS,1998).

As condições de trabalho formam uma importante variável na análise da qualidade de vida e saúde, os professores, em especial, formam uma categoria profissional especialmente sujeita a grandes riscos psicossociais, pois a prática docente pode ser uma atividade altamente estressante, podendo trazer reflexos negativos para a saúde física e mental, bem como, para o desempenho profissional.

Apesar disso, a qualidade de vida e as condições de trabalho de professores de educação superior ainda são desconhecidas em muitas realidades brasileiras, sendo assim, este trabalho pretende conhecer o cotidiano profissional dos professores do Curso de Administração da UNESC e conhecer suas propostas de melhorias para o desenvolvimento da docência.

Acredita-se que o conhecimento da associação de diferentes aspectos das condições de trabalho dos professores, pode apontar, de forma objetiva, pontos para intervenções e nortear políticas institucionais para o bem-estar dos docentes na Universidade. Desta forma, este estudo tem como tema: Estudo quantitativo da percepção da qualidade de vida no trabalho, na visão dos Professores do curso de Administração da UNESC. Como problema de pesquisa foi elaborada a seguinte questão: Qual a visão dos professores do Curso de Administração da UNESC sobre a sua qualidade de vida no trabalho?

O Curso de Administração da UNESC possui em seu quadro docente, profissionais que, paralelo a docência, possuem outra carreira profissional, e este é um fator importante, pois proporciona aos mesmos, a possibilidade de aliar teoria e prática, por outro lado, aumenta a carga de trabalho, podendo comprometer a qualidade de vida.

Atualmente, a qualidade de vida vem sendo alvo de estudos e debates. No que tange ao trabalho docente, estas discussões tem acontecido com freqüência, pois a docência, além da aula ministrada, acarreta trabalhos extraclasse, como: preparação das aulas, correção de provas e demais atividades pedagógicas.

Outro fator gerador de consumo de tempo, é que os professores são constantemente 'convidados' a participarem de formação continuada, apresentar produção científica, cursarem mestrados e doutorados, pois para a universidade, a qualificação é necessária e de extrema importância, pois, além da titulação, os professores devem envolver-se com ensino, pesquisa e extensão. 
Essas exigências, bem como a sobrecarga de trabalho vêm gerando estresse e outras síndromes, interferindo na qualidade de vida. Sendo assim, esta pesquisa buscará informações sobre o cotidiano dos professores e a visão dos mesmos acerca da qualidade de vida.

Este estudo é fomentado pela necessidade de se verificar as condições de trabalho dos docentes do curso, o principal objetivo é Conhecer a visão dos professores do Curso de Administração da UNESC sobre a sua qualidade de vida no trabalho. Para subsidiar o estudo, foram destacadas as seguintes ações:

- Identificar o perfil dos professores do Curso;

- Identificar a percepção dos professores acerca da docência e do ambiente de trabalho.

- Detectar propostas de melhoria no ambiente de trabalho para melhorar a qualidade de vida.

\section{UNIVERSIDADE DO EXTREMO SUL CATARINENSE - UNESC ${ }^{1}$}

A UNIVERSIDADE DO EXTREMO SUL CATARINENSE (UNESC) é uma Instituição de Ensino Superior (IES), com duração indeterminada, com sede em Criciúma - SC, mantida pela Fundação Educacional de Criciúma (FUCRI), entidade de personalidade jurídica de direito privado, de fins filantrópicos e não lucrativos, com sede e foro na cidade de Criciúma, Estado de Santa Catarina, inscrita no CNPJ/MF sob n. 836610740001/04, situada à Avenida Universitária, n. 1105 - Bairro Universitário, CEP 88806-000.

A UNESC é resultado de uma grande mobilização social, constituída em meados dos anos 1960, devido à ausência de uma instituição de ensino superior em Criciúma e região. A partir dela surgia, em 1968, a FUCRI (Fundação Educacional de Criciúma), criada pela lei municipal no 697, no dia 22 de junho, como uma instituição pública não estatal, que se transformaria, no futuro, na mantenedora e no embrião da Universidade.

Missão Institucional: Educar, por meio do ensino, pesquisa e extensão, para promover a qualidade e a sustentabilidade do ambiente de vida.

Visão de Futuro: Ser reconhecida como uma Universidade Comunitária, de excelência na formação profissional e ética do cidadão, na produção de conhecimentos científicos e tecnológicos, com compromisso sócio-ambiental.(Aprovada em 28/03/2008)

Estratégias e Objetivos Institucionais: A UNESC estabeleceu os quatro eixos norteadores da instituição, os quais foram definidos como estratégias institucionais:

1 Todos os dados e referenciais apresentados sobre a UNESC, foram extraídos na íntegra do Plano de Desenvolvimento Institucional - PDI. 


\subsection{INSERÇÃO REGIONAL}

A Universidade do Extremo Sul Catarinense - UNESC - está situada em Criciúma, no sul de Santa Catarina. O município abrange uma área de $236 \mathrm{~km}^{2}$ e possui, aproximadamente, 188.233 habitantes ${ }^{2}$. Em sua origem, contou com o trabalho fundamental de colonizadores europeus, com destaque para os italianos, alemães, poloneses e portugueses e, posteriormente, os negros, vindos de outras regiões do país. Essas etnias tiveram influência significativa no desenvolvimento, não só da cidade de Criciúma, mas também das demais que compõem o sul de Santa Catarina.

A região ocupa uma área de $9.049 \mathrm{~km}^{2}$, equivalente a 9,8\% do território do Estado. Compreende 39 municípios e abriga uma população estimada em 800 mil habitantes, dos quais cerca de 500 mil moram nas áreas urbanas. Está dividida em três microrregiões, assim designadas: Associação dos Municípios da Região de Laguna (AMUREL), Associação dos Municípios da Região Carbonífera (AMREC) e Associação dos Municípios do Extremo Sul Catarinense (AMESC).

\subsection{PERFIL DO CORPO DOCENTE DA UNESC}

O corpo docente da UNESC é constituído por $\mathbf{6 0 8}$ professores atuantes, sendo $\mathbf{5 6 8}$ $(93,42 \%)$ do quadro regular e $\mathbf{4 0}(6,58 \%)$ do quadro especial. Atualmente o quadro de docentes da Universidade possui a titulação especificada no quadro a seguir:

Quadro 1 - Corpo Docente por Titulação Acadêmica

\begin{tabular}{|l|l|l|l|}
\hline Titulação & Número & Quadro Regular & Quadro Especial \\
\hline Graduado & 35 & 22 & 13 \\
\hline Especialista & 280 & 261 & 19 \\
\hline Mestre & 230 & 222 & 08 \\
\hline Doutor & 63 & 63 & -- \\
\hline Total Geral & 608 & $568(93,42 \%)$ & $40 \quad(6,58 \%)$ \\
\hline
\end{tabular}

Fonte: Recava - Reconhecimento e Avaliação de Cursos (Setembro/ 2008)

Na contratação do corpo docente para as atividades acadêmicas, a UNESC fundamentase no Plano de Carreira do Corpo Docente, que define os seguintes regimes de trabalho:

I. Tempo integral - é enquadrado neste regime o docente contratado para cumprir uma carga horária de quarenta horas semanais, distribuídas nas atividades de ensino, pesquisa, extensão e administração universitária.

2 População estimada em 2006 pelo IBGE. 
II. Horista - é enquadrado neste regime o docente contratado para uma carga horária inferior ou igual a quarenta horas semanais em atividades de ensino, pesquisa, extensão e administração universitária.

A carga horária no regime de trabalho horista é definida semestralmente e corresponde às atividades assumidas pelo docente.

O docente com regime de trabalho de tempo integral cumpre a sua carga horária em horário e local aprovados pela direção da Unidade Acadêmica qual pertence sendo distribuídas nas seguintes atividades:

\section{Ensino.}

II. Pesquisa.

III. Extensão.

IV. Administração universitária.

V. Demais atividades decorrentes da docência.

Das 40 (quarenta) horas previstas no regime de trabalho em tempo integral, $50 \%$ (cinqüenta por cento) são destinadas a atividades de ensino, 30\% (trinta por cento) as atividades de pesquisa, extensão e/ou administração universitária e $20 \%$ (vinte por cento) para as demais atividades decorrentes da docência. No quadro 4, observa-se melhor tais números.

Quadro 2-Regime Trabalho dos Docentes

\begin{tabular}{|l|l|l|l|}
\hline Situação & Total & Quadro Regular & Quadro Especial \\
\hline Horista $(01$ a 39h/a) & 425 & 385 & 40 \\
\hline Integral $(40$ h/a) & 183 & 183 & -- \\
\hline Total Geral & 608 & $568(93,42 \%)$ & $40 \quad(6,58 \%)$ \\
\hline
\end{tabular}

Fonte: Universidade do Extremo Sul Catarinense ( 2008)

\subsubsection{Constituem o corpo docente da Universidade}

I. Professores do quadro especial: substitutos, visitantes e colaboradores.

II. Professores integrantes do quadro regular.

O professor do quadro especial é aquele contratado mediante análise de currículo, com titulação mínima de Especialização, por período determinado, para substituir professor afastado temporariamente de suas atividades ou para suprir necessidades emergenciais da Universidade. 
Considera-se docente do quadro regular aquele que, contratado por tempo indeterminado por processo seletivo amplamente divulgado, com titulação mínima de especialista, realiza atividades de ensino, pesquisa, extensão ou administração universitária, sendo seu enquadramento realizado em uma das categorias organizadas de I a VII, com destaque a titulação, experiência na docência e produção científico-acadêmica, requisitos para progressão definido no Plano de Carreira do Corpo Docente conforme quadro abaixo:

Quadro 3 - Categorias do Quadro Regular Docente

\begin{tabular}{|l|l|}
\hline CATEGORIA & TITULAÇÃO \\
\hline I & Graduado \\
\hline II & Especialista Mestre Iniciante \\
\hline III & Especialista/Mestre/ Doutor iniciante \\
\hline IV & Mestre/ Doutor \\
\hline V & Mestre/ Doutor \\
\hline VI & Doutor \\
\hline VII & Doutor \\
\hline & Doutor \\
\hline
\end{tabular}

Fonte: Universidade do Extremo Sul Catarinense ( 2007)

A admissão do docente no quadro regular do presente Plano de Carreira é realizado por meio de Processo Seletivo regulamentado pelo Conselho Universitário - CONSU e realizado pelo Departamento de Desenvolvimento Humano.

\subsection{QUALIDADE DE VIDA NO TRABALHO (QVT)}

A melhoria da saúde por meio de novas formas de organizar o trabalho tem sido objeto de inúmeros estudos. No Brasil, tem despertado interesse de empresários e pesquisadores, pelo reflexo positivo na satisfação do colaborador e em sua produtividade, a qualidade de vida no trabalho é afetada, ainda, por questões comportamentais que dizem respeito as necessidades humanas e aos tipos de comportamentos individuais no ambiente de trabalho. (LIMONGI-FRANÇA, 2007).

A busca da QVT é uma preocupação que envolve pessoas, trabalho e organização, em busca do bem estar e do envolvimento do colaborador, por meio da qualidade e produtividade. Esta busca, deve ser iniciada pelas pessoas, pois não existe programa bem sucedido sem a efetiva preocupação com a qualidade de vida dos envolvidos. (RODRIGUES; AMORIM,1995)

Neste sentido, a QVT é considerada importante independe da região, época ou local de trabalho. O desafio é que as pessoas estejam bem, nos aspectos físicos e psicológicos, sintam-se integradas e valorizadas. 
De acordo com Machado ( 2009, p. 30), a qualidade de vida no trabalho é apontada com sucesso, abrangendo:

Renda capaz de satisfazer as expectativas pessoais e sociais; Orgulho pelo trabalho realizado;Vida emocional satisfatória; Autoestima; Imagem da instituição junto a opinião pública; Equilibrio entre trabalho e lazer; Horários e condições de trabalho coerentes; Oportunidade e perspectiva de carreira; Possibilidade do uso do potencial; Respeitos aos direitos; Justiças nas recompenças.

Com essas considerações, pode-se questionar sobre como obter qualidade de vida na Instituição de Ensino Superior ${ }^{3}$ para o seu corpo docente.

Inicialmente os docentes necessitam sentir-se parte da Instituição, participando integralmente de seus planejamentos, conhecendo seus objetivos e principalmente suas necessidades, mas isso se torna difícil para docentes que trabalham como horistas, ou seja, apenas têm uma parte da sua jornada de trabalho desenvolvida na IES.

Essa situação pode ser estendida para aqueles que, mesmo possuindo um vínculo maior com a IES, pelo menos vinte horas de trabalho, mas possuem concomitante, uma carga horária profissional fora da sala de aula, de igual ou maior dedicação semanal, sobrecarregando seus horários de trabalho.

Os conceitos de Qualidade de Vida e Qualidade de Vida no Trabalho são diversificados e requer esforços com o objetivo de se aprofundar na literatura científica para compreendêlos, pois revelam preocupação com relação ao equilíbrio, satisfação pessoal e profissional, além de bem-estar.

Segundo Dejours (1992), as pressões recorrentes das organizações de trabalho podem ser desestabilizadoras para a saúde mental do trabalhador. O mesmo autor explica a 'organização de trabalho' através da divisão do trabalho ou o modo operário descrito como de fato ocorre e associa a idéia de repartição, de responsabilidades, hierarquia e controle.

Podemos destacar Tumer e Lawrence (1965 apud Codo, 1999) que apresentaram um estudo do comportamento do trabalhador, cujas tarefas incluíam seis atributos: Variedade, Autonomia, Interação exigida, Interação operacional, Conhecimento, Habilidade, Responsabilidade.

Segundo Rodrigues (1999, apud Vasconcelos, 2001), a qualidade de vida sempre teve a atenção do ser humano, sendo contextualizada de várias formas, e estando sempre voltada a facilitar ou trazer satisfação e bem-estar ao trabalhador na execução de suas tarefas.

O autor considera que a Q.V.T. tem sua origem marcada em 300 a.C., pela contribuição de Euclides de Alexandria, para a melhoria do método de trabalho dos agricultores à 
margem do rio Nilo, e, em 287 a.C., por Arquimedes ao propor a Lei de alavancas, para diminuir o esforço físico dos trabalhadores.

Segundo Vasconcelos (2001), é relevante mencionar o trabalho de Frederick Hezberg, cuja Teoria de dois fatores associava a insatisfação do funcionário com o trabalho ao ambiente de trabalho e ao trabalho em si. Os fatores higiênicos para a produção de insatisfação compreendem: a política e a administração da empresa, as relações interpessoais com os supervisores, supervisão, condições de trabalho, salários, status e segurança no trabalho. Os fatores motivacionais de satisfação abrangem: realização, reconhecimento, o próprio trabalho, responsabilidade e progresso ou desenvolvimento. Ressalta-se, portanto, que os desafios enfrentados por idealizadores continuam, isto é, tornam a QVT uma ferramenta gerencial e não mais um processo passageiro. Nota-se que, nos dias atuais, o indivíduo tem trabalhado cada vez mais, e por conseqüência, tem tido menos tempo para si mesmo (VEIGA; CASTANHO, 2000). Baseando-se nessa realidade, Handy (1995, p.25), declarou que: "o problema começou quando transformamos o tempo em uma mercadoria, quando compramos o tempo das pessoas em nossas empresas em vez de comprar a produção".

\subsection{SÍNDROME DE BURNOUT ${ }^{4}$}

De acordo com Carlotto (2002), os professores têm sido alvo de diversas investigações, pois nos trabalhos desenvolvidos por pessoas, enquanto professores, observam-se agentes de estresse psicossociais, uns, pelos princípios das funções, outros, em razão do contexto em que se inserem, seja institucional e/ou social, onde são desenvolvidos. Quando estes estresses se tornam constantes, eventualmente, podem conduzir à Síndrome de Burnout, tidas como um tipo de estresse de caráter persistente vinculado a situações de trabalho, resultante da constante e repetitiva pressão emocional associada com intenso envolvimento com pessoas por longos períodos de tempo.

Burnout em docentes interfere no meio discente e afeta o atingimento das metas pedagógicas, induzindo os professores a um método de vinculação, contribuindo para o aparecimento de dificuldades na sua saúde e ausência e disposição de afastar-se de seus afazeres profissionais. (GUGLIELMI; TATROW, 1998 apud CARLOTTO, 2002).

Burnout é uma espécie de estresse do trabalho, atingindo trabalhadores que se preocupam, demasiadamente, numa afinidade emocional. As profissões mais vulneráveis são geralmente as que envolvem serviços, tratamento ou educação. (MASLACH; LEITER, 1999 apud CARLOTTO, 2002).

O conceito de burnout com maior aprovação está pautado na expectativa socialpsicológica de Maslach (1999, apud CARLOTTO, 2002) formada por três dimensões: exaustão emocional, despersonalização e baixa realização pessoal no trabalho.

4 A teoria de Burnout apresenta vários apud's, pois os autores citados pela pesquisadora Mary Sandra Carlotto ( que foi a pesquisadora estudada), estão apresentados em inglês e Francês. 
Maslach, Schaufeli e Leiter (2001 apud CARLOTTO, 2002), assim definem as três dimensões da síndrome:

- Exaustão Emocional: caracterizada por uma falta ou carência de energia, entusiasmo e um sentimento de esgotamento de recursos

- Despersonalização: caracteriza-se por tratar os clientes, colegas e a organização como objetos.

- Diminuição da realização pessoal no trabalho: tendência do trabalhador a se auto-avaliar de forma negativa.

As pessoas sentem-se infelizes consigo próprias e insatisfeitas com seu desenvolvimento profissional.

O processo do burnout é individual. A evolução deste processo poderá acontecer em anos ou em em períodos maiores. (RUDOW, 1999 apud CARLOTTO, 2002). O aparecimento é lento, porém, acumulado, com tendência para casos severos (FRANÇA, 1987, apud CARLOTTO, 2002), invariavelmente passando desapercebido pelo portador, que normalmente não crê que possa estar sendo acometido pelo burnout. (FRANÇA, 1987; ; DOLAN, 1987; RUDOW, 1999 apud CARLOTTO, 2002).

\subsubsection{Identificando o Burnout}

Farber (1991 apud CARLOTTO, 2002) define as aparições do burnout em docentes, como sinais individuais e profissionais. Normalmente, os docentes apresentam-se com o emocional e o físico cansados, irritadiços, apreensivos, raivosos ou tristes. Estes sintomas podem causar outros sintomas, como insônia, enxaqueca e pressão alta. Profissionalmente, o docente ensejará danos nos planos de trabalho e, ainda, apresentará faltas constantes ao trabalho e sinais de descuidos.

Segundo Edelwich e Brodsky (1980 apud Carlotto, 2002), os docentes com sinais de burnout, usam seu tempo para menosprezar os discentes, falar mal da administração e, invariavelmente, desdenham sua opção profissional, fazendo planos para novas conquistas. 
Quadro 4 - Listagem dos sintomas associados ao Burnout

- Ironia e cinismo: são atitudes que aparecem quando a pessoa apresenta insatisfação e hostilidade para com os colegas.

- Ímpetos de abandonar o trabalho: surge quando a pessoa passa a pensar muito sobre o assunto e torna-se uma alternativa cada vez

SINTOMAS

DEFENSIVOS

SINTOMAS

DEFENSIVOS maior.

- Absenteísmo: as faltas passam a ser uma possibilidade de sentirse aliviada.

- Perda de interesse pelo trabalho (ou até pelo lazer): todas as atividades passam a serem árduas.

- Sentimento de onipotência: para compensar sensações de frustração e incapacidade, reagem com imagem de autosuficientes.

- Tendência ou isolamento: as pessoas tendem a se distanciar do outro, para minimizar a sensação de fracassado e insuficientes. 
- Perturbações gastrointestinais: podendo ir desde uma "queimação" estomacal, gastrites, até a uma úlcera. Há pessoas que perdem o apetite, emagrecendo rapidamente e outras aumentam o consume de alimentos, que ganham excesso de peso;

- Alterações menstruais: atraso ou até suspensão da menstruação nas mulheres;

- Disfunções sexuais: diminuição do desejo sexual. Para os homens ejaculação precoce ou impotência. Para as mulheres dores na relação e anorgasmia;

- Distúrbios do sistema respiratório: bronquite, asma, dificuldade para respirar, suspiros profundos;

SINTOMAS FÍSICOS

SINTOMAS COMPORTAMENTAIS
- Transtornos cardiovasculares: hipertensão arterial, palpitações, insuficiência cárdio-respiratória, ocorrendo até mesmo infartos e embolias;

- Imunodeficiência: diminuição da resistência física, ocasionando resfriados ou gripes contínuos, alergias, herpes, queda do cabelo;

- Cefaléias, enxaquecas: são dores do tipo tensional.

- Dores musculares ou osteomusculares: dores na nuca, nos ombros, na coluna;

- Distúrbio do sono: apesar do cansaço a pessoa não consegue dormir imediatamente. Tendo pesadelos e sono agitado.

- Fadiga constante e progressiva: sensação de falta de energia, de vazio interior

- Dificuldade na aceitação de mudanças: indica dificuldade em aceitar e se adaptar a novas situações. Apresentando comportamento estereotipado, mais rígido. 
- Incapacidade para relaxar: apresenta sempre estar em situações de alerta, ativa, não consegue relaxar e aproveitar até mesmo momentos prazerosos.

- Incremento da agressividade: apresenta comportamentos agressivos, mesmo não tendo motivos para reagir desta forma.

- Irritabilidade: demonstra pouca paciência com o outro. Podendo aumentar em pessoas que dormem mal.

- Negligência ou escrúpulo excessivo: descuido em suas atividades

\section{SINTOMAS} COMPORTAMENTAIS ocupacionais podendo ocorrer acidentes de trabalho.

- Perda de iniciativa: a pessoa prefere fazer as mesmas coisas, que procurar mudar sua rotina, para não ter que tomar iniciativas.

- Aumento do consumo de substância: como bebidas alcoólicas, cafezinho, cigarros, tranqüilizantes, etc.

- Comportamento de alto risco: as pessoas que se sentem incapazes podem procurar atividades de alto risco para minimizar esse sentimento.

- Suicídio: o índice é maior com profissionais da área da saúde do que a população em geral.

- estão se aproveitando de seu trabalho, e que não pode mais contar com os outros. Levando a paranóia que as pessoas estão contra ela, fazendo uma armadilha para prejudicá-la;

- Astenia, desânimo, disforia, depressão: há um declínio do estado de animo, perda do entusiasmo, levando a uma repentina mudança do estado de ânimo e a depressão;

- Desconfiança, paranóia: a pessoas passa a pensar que as pessoas;

SINTOMAS PSÍQUICOS
- Dificuldade de auto-aceitação, baixa auto-estima: traz consigo uma sensação de insuficiência, de fracasso, levando a arruinar sua auto-imagem;

- Labilidade emocional: mudança brusca de humor, podendo em um momento estar bem, e outro em um estado de tristeza ou agressividade, sem apenas um motivo;

- Sentimento de impotência: sensação de que nada consegue fazer;

- Impaciência: torna-se intolerante com atrasos, e esperar passa a ser insuportável. 
- Sentimento de solidão: a pessoa se sente só, não compreendida pelos demais;

- Sentimentos de alienação: sente-se distante do ambiente e das pessoas que a rodeiam, como se as coisas fossem irreais.

SINTOMAS Lentificação do pensamento: os pensamentos e as respostas do PSÍQUICOS organismo tornasse lento.

- Alterações de memória: apresentam lapsos de memória, onde a pessoas muitas vezes perdem a linha do raciocínio.

- Falta de atenção de concentração: dificuldade de manter a atenção naquilo que esta fazendo; tenta se concentrar por alguns instantes e se distrai logo em seguida.

Fonte: Vieira ( 2008, p. 19-20).

\subsubsection{Principais Causas}

Farber (1991 apud Carlotto, 2002) parte do princípio de que os sintomas do burnout são uma mistura de causas individuais, organizacionais e sociais e, a integração destas construiria uma visão de menosprezo profissional. Quando se refere à personalidade, a teoria leva em consideração docentes idealizadores e alegres com sua profissão, mais suscetíveis a vulnerabilidade, porque acreditam que possam perder algo. Entretanto, estes docentes comprometem-se com suas atividades e se envolvem fortemente com 0 trabalho, ficando decepcionados por não verem seus esforços valorizados. (MASLACH; JACKSON,1984 apud CARLOTTO, 2002).

Para Etzion (1987 apud Carlotto, 2002), as perguntas comuns vinculadas a socialização e a organização social, estão associadas às diferenças que ocorrem nos níveis do burnout. Os docentes com até 40 anos sofrem maior incidência, por se frustarem com a profissão.

Segundo Maslach (1982 apud Carlotto, 2002), docentes mais idosos tem mais segurança na profissão que escolheram e optam por permanecer nela, estando menos preocupados com os sintomas relacionados ao estress.

Friedmann (1991 apud Carlotto, 2002) estabelece que a experiência profissional avantajada do docente, conduz para níveis menores do Burnout.

Essencial na docência, o contato com o discente, aparece como uma das principais causas do Burnout. O docente apresenta características incoerentes a sua satisfação.

O professor adota muitas funções, possui papéis muitas vezes contraditórios, isto é, a instrução acadêmica e a disciplina da classe. Também têm que lidar com aspectos sociais e emocionais de alunos, e ainda conflitos ocasionados pelas expectativas dos pais, estudantes, administradores e da comunidade. 


\begin{abstract}
O excesso de tarefas burocráticas tem feito com que professores se sinta desrespeitados, principalmente quando devem executartarefas desnecessárias e não relacionadas à essência de sua profissão. Ao desempenhar trabalhos de secretaria, diminui sua carga horária para o atendimento ao aluno e para desenvolver-se na profissão. A falta de autonomia e participação nas definições das políticas de ensino tem mostrado ser um significativo antecedente do burnout.(CARLOTTO, 2002, p. 25)
\end{abstract}

Estes fatores, somados à inadequação salarial e à falta de oportunidades de promoções, têm preocupado pesquisadores, outra questão relevante apontada pela autora é o isolamento social e a falta de senso de comunidade que, geralmente, estão presentes no trabalho docente, tornando os professores mais vulneráveis ao burnout (CARLOTTO, 2002). Segundo os autores Burke e colaboradores (1996), o ensino é uma profissão solitária, uma vez que há uma tendência do professor a vincular suas atividades ao atendimento de alunos, ficando à parte de atividades de afiliação, grupos e engajamento social.

\title{
2.4.3 Modelos Explicativos de Burnout em Professores
}

De acordo com Carlotto (2002, p. 25), “Burnout em professores é um fenômeno complexo e multidimensional resultante da interação entre aspectos individuais e o ambiente de trabalho. Este ambiente não diz respeito somente à sala de aula ou ao contexto institucional, mas sim a todos os fatores envolvidos nesta relação, incluindo os fatores macrossociais, como políticas educacionais e fatores sócio-históricos".

Vários autores e modelos têm tentado explicar a síndrome de burnout em professores a partir de diversas perspectivas. Ainda, conforme Carlotto(2002) os fatores micro são os que se situam dentro da biografia pessoal e profissional do professor (comprometimento, valores, carreira e papéis desenvolvidos). Os fatores meso ou intermediários são os institucionais (tipo de escola, aspectos éticos da escola, aspectos culturais do professor e dos alunos) e os macro são todas as forças derivadas das tendências globais e políticas governamentais. Estes níveis em interação desencadeiam o processo de 'desprofissionalização' do trabalho do professor.

Os professores, de acordo com esta visão, são mais técnicos do que profissionais. Kelchtermans (1999 apud Carlotto, 2002) acredita que este modelo está vinculado à concepção de escola como 'empresa', com critérios de avaliação e controle baseados nos valores de eficiência burocrática e medidas padronizadas de seus resultados.

Lampert (1999, p. 27 apud Carlotto, 2002) diz que a "educação hoje é vista e gerenciada como um negócio rentável. A comunidade, de uma forma geral, nota esta concepção de ensino, desenvolvendo uma percepção negativa em relação à mesma, com conseqüente desprestígio de todos os que dela fazem parte".

Lens e Jesus (1999, p. 28 apud Carlotto, 2002), afirmando que o "status da profissão de professor e de outras vem declinando nos últimos anos e isto tem contribuído para o aumento do burnout nesta categoria profissional". 


\section{PROCEDIMENTOS METODOLÓGICOS}

A metodologia da pesquisa trata da proposta de discutir e avaliar as características da ciência e de outras formas de conhecimento, a abordagem metodológica enfoca o planejamento de projetos, ressaltando a elaboração e a execução do mesmo.

Segundo Marconi e Lakatos (2002, p. 71) a finalidade da metodologia da pesquisa é:

[...] colocar o pesquisador em contato direto com tudo o que foi escrito, dito ou filmado sobre determinado assunto, inclusive conferencias seguidas de debates que tenham sido transcritos por alguma forma, quer publicadas quer gravadas.

De acordo com Appolinário (2004, p. 132) “Método é a seqüência lógica de procedimentos que deve ser seguido para a consecução de um objetivo".

\subsection{TIPOS DE PESQUISA}

Para a classificação da pesquisa, tomam-se como base dois aspectos: quanto aos fins e quanto aos meios.

Quanto aos fins, a pesquisa foi descritiva, pois visou descrever percepções, expectativas e sugestões dos professores do Curso de Administração e Administração com Habilitação em Comércio Exterior da Universidade do Extremo Sul Catarinense - UNESC, acerca da percepção da qualidade de vida no trabalho na visão dos mesmos.

Quanto aos meios, a pesquisa foi bibliográfica e de campo. Bibliográfica, pois a fundamentação teórica foi estruturada com base em estudos de autores que já realizaram publicações científicas acerca do assunto em estudo.

De campo, pois realizou-se uma investigação empírica com os docentes do curso em estudo, utilizando como instrumento de levantamento de dados, um questionário. (VERGARA, 2009)

\subsubsection{Pesquisa Bibliográfica}

Para a elaboração deste estudo, foi realizada uma pesquisa bibliográfica, pois se trata do primeiro passo para um estudo aprofundado de pesquisa científica. Esta se refere ao levantamento de dados e informações sobre uma bibliografia já publicada.

De acordo com Vergara (2009, p. 43) “A Pesquisa bibliográfica é o estudo sistematizado desenvolvido com base em material publicado em livros, revistas, jornais, redes eletrônicas, isto é, material acessível ao público em geral." 


\subsubsection{Pesquisa Descritiva ou de Campo}

A Pesquisa descritiva expõe características de determinada população ou de determinado fenômeno, pode, também, estabelecer relações entre o objeto de estudo e a população estudada. Não tem a função de explicar os fenômenos que descreve, entretanto, oferece subsídios para a fundamentação da explicação. (VERGARA, 2009)

Para iniciar a pesquisa de campo, foi entregue ao Coordenador do Curso uma solicitação de permissão para a realização da pesquisa, juntamente com o questionário em anexo, para que o mesmo tivesse conhecimento dos questionamentos.

A Pesquisa de campo foi realizada entre os dias 07 e 15 de outubro de 2010, os questionários foram entregues em mãos aos professores e recolhidos no mesmo dia em que os mesmos receberam.

\subsection{ABORDAGEM DA PESQUISA}

Foram utilizadas nesta pesquisa as abordagens qualitativas e quantitativas. A abordagem quantitativa possui importância para medir opiniões, comportamentos, atitudes e preferências. Deve envolver dados numéricos para que possa ser trabalhado com procedimentos estatísticos específicos adequado a sua situação.

De acordo com Vianna (2001, p. 122) a maneira quantitativa "trabalhará com propostas de investigação de pesquisa, hipóteses, variáveis, significância estatística, plano estruturado e detalhado dos procedimentos de trabalho, contagem, medidas".

Já a abordagem qualitativa trabalha com análise de cada situação ocorrida a partir de dados descritivos, visando identificar as relações, causa, efeitos, conseqüências, opiniões, significados e outros pontos importantes para a compreensão da realidade estudada. Neste estudo a abordagem principal da pesquisa é o contato direto entre o pesquisador e o pesquisado, de forma a transmitir uma segurança, amizade, e confiança para que se possa garantir uma pesquisa neutra e poder alcançar os objetivos do estudo.

Conforme cita Chizzotti (2005, p. 83):

Cria-se uma relação dinâmica entre pesquisador e o pesquisado que não será desfeita em nenhuma etapa da pesquisa [...] o resultado final da pesquisa não será fruto de um trabalho meramente individual, mas uma tarefa coletiva, gerada em muitas micro decisões, que a transformam em uma obra coletiva.

O resultado que se planejou alcançar possuiu a importância de observar como os empreendedores estão driblando suas dificuldades, pois através de dados recolhidos pelos entrevistados foi possível conhecer quais são estes problemas e tentar obter uma solução para a resolução destes. 


\subsection{POPULAÇÃO E AMOSTRA}

A população pesquisada foi composta pelos professores do curso de Administração e Administração com Habilitação em Comércio Exterior da UNESC. Atualmente o curso conta com 41 professores.

Foram considerados todos os docentes do quadro do curso de Administração, exceto aqueles afastados por qualquer motivo. No próprio campus foram feitos os contatos com os docentes do curso, explicando o objetivo da pesquisa e convidando-os para participar.

A amostra escolhida foi intencional, ou seja, igual à população pesquisada. Dos 41 docentes pesquisados, 38 docentes responderam o questionário, perfazendo $\mathbf{9 3 \%}$ da amostra, sendo que todos tiveram total liberdade para responder ou não.

\subsection{INSTRUMENTO DE COLETA DE DADOS}

Neste estudo foi utilizado como instrumento de coleta de dados um questionário composto por 15 perguntas fechadas e um espaço para criticas ou sugestões, que segundo Appolinário (2004, p. 168) “É uma técnica estruturada para coleta de dados [...] que consiste num conjunto de perguntas escritas que deve ser respondida pelos sujeitos". O questionário proposto foi entregue aos professores do Curso de Administração e Administração com Habilitação em Comércio Exterior da UNESC.

De acordo com Appolinário (2004, p. 114) Instrumento é: “o meio através do qual se mensura determinado fenômeno ou se obtêm dados numa pesquisa."

Segundo Oliveira (1999. p 182) "na prática da pesquisa inicia-se com a aplicação dos instrumentos elaborados e das técnicas selecionadas, a fim de se efetuar a coleta de dados previstos".

Depois de coletadas as informações necessárias, as mesmas foram tabuladas em forma de tabelas e/ou gráfico para análise.

\subsection{CARACTERIZAÇÃO DO AMBIENTE DE PESQUISA}

A experiência de pesquisa foi realizada no Curso de Administração da UNESC, localizado no Bloco ' $R$ ', o curso conta, atualmente, com aproximadamente 900 alunos, é ofertado nos turnos matutino e noturno.

\section{EXPERIÊNCIA DE PESQUISA}

Neste capítulo apresentam-se os dados advindos da coleta de dados realizada com os docentes do Curso de Administração da UNESC. 


\subsection{PERFIL DOS ENTREVISTADOS}

Figura 1 - Gênero

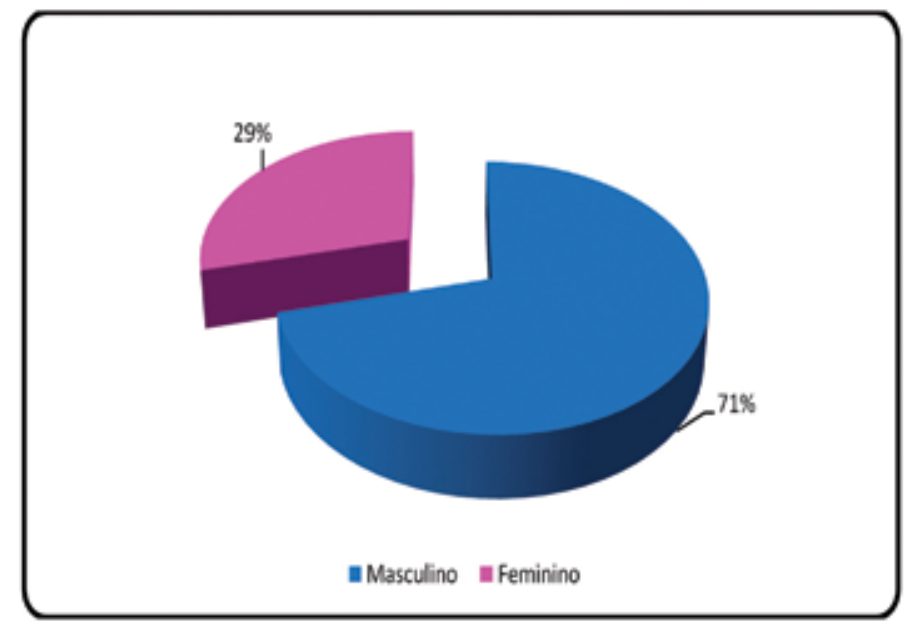

Fonte: Dados da Pesquisa

A pesquisa mostrou que a maioria dos docentes do curso de Administração é do sexo masculino, este dado nos leva a "entender" que as empresas ainda são administradas em sua maioria por homens, pois, conforme nos mostra outro dado levantado, grande parte dos docentes trabalham em organizações dos mais variados seguimentos.

Figura 2 - Idade

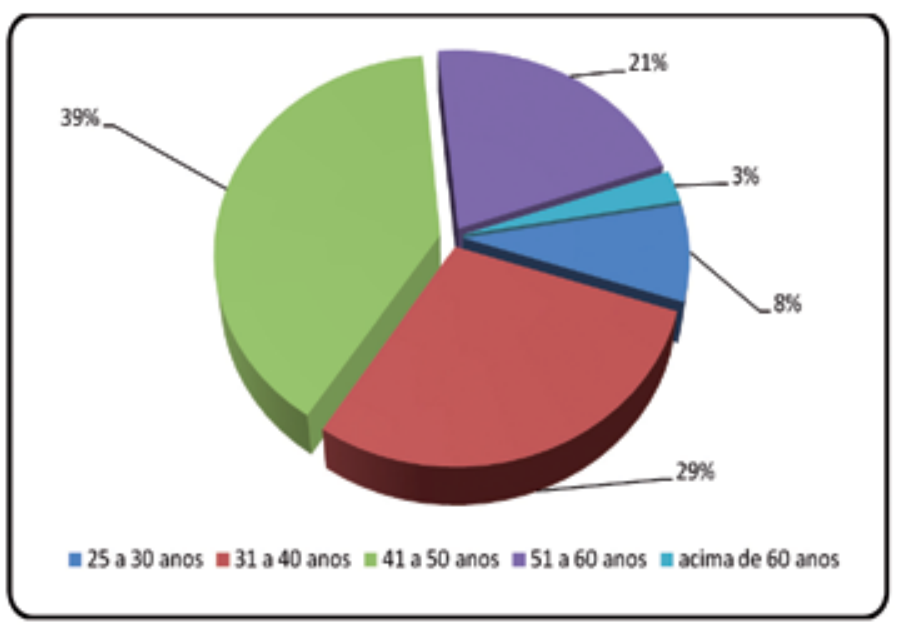

Fonte: Dados da Pesquisa

O corpo docente do curso de Administração é formado por pessoas relativamente jovens, pois a maioria tem menos de 50 anos. Portanto, é um grupo que apresenta condições de buscar qualificações para manter-se ativo no curso. 
Figura 3 - Estado Civil

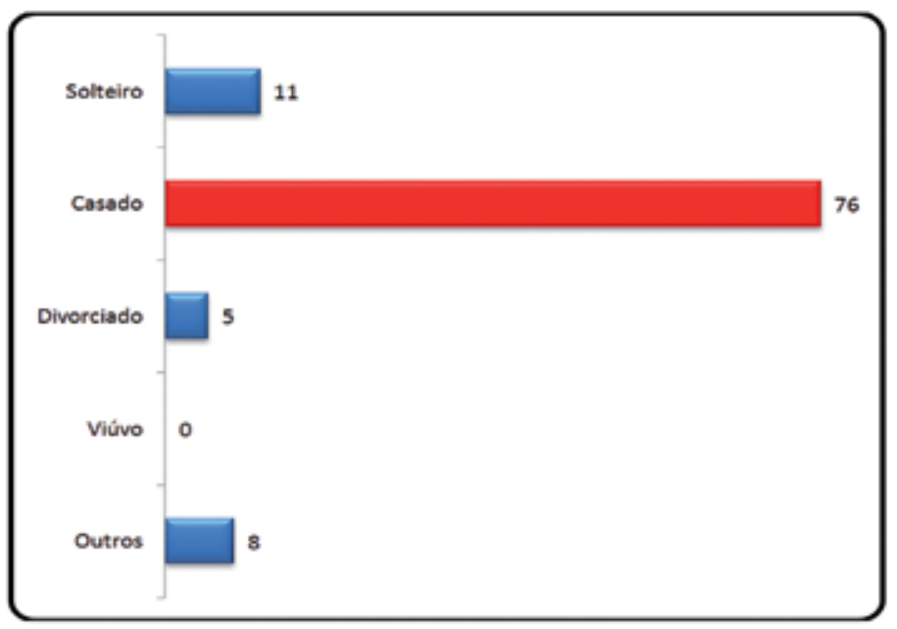

Fonte: Dados da Pesquisa

A Pesquisa demonstrou que a maioria dos docentes é casado, levando a entender que, além das atividades desenvolvidas na docência, os mesmos têm compromissos familiares.

Figura 4 - Tempo de trabalho na UNESC

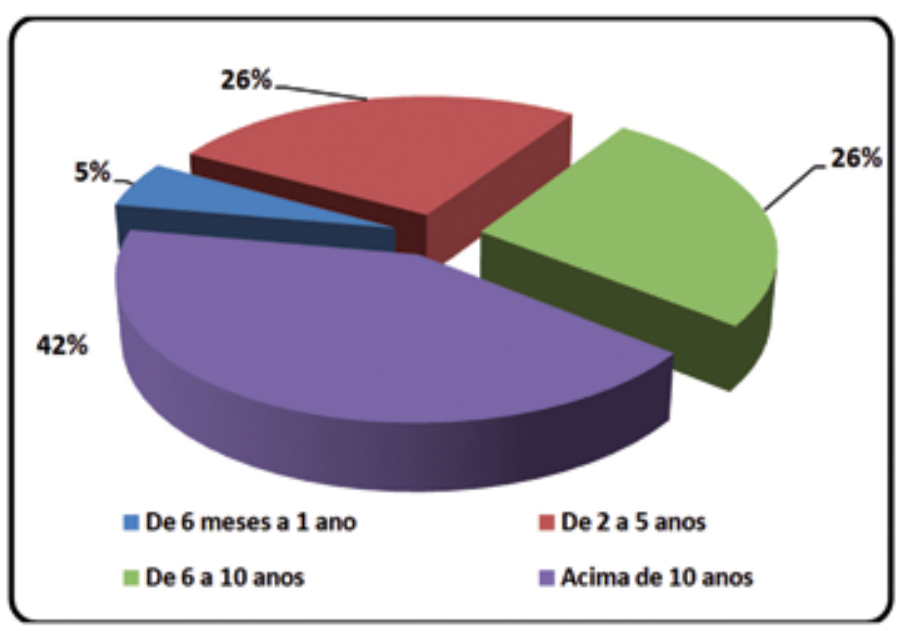

Fonte: Dados da Pesquisa

Com base nos dados coletados, verificou-se que a maioria dos docentes do curso de Administração está há mais de 06 anos na instituição, este dado, revela que os mesmos gostam de ser docentes da UNESC e participar do colegiado do Curso de Administração. 


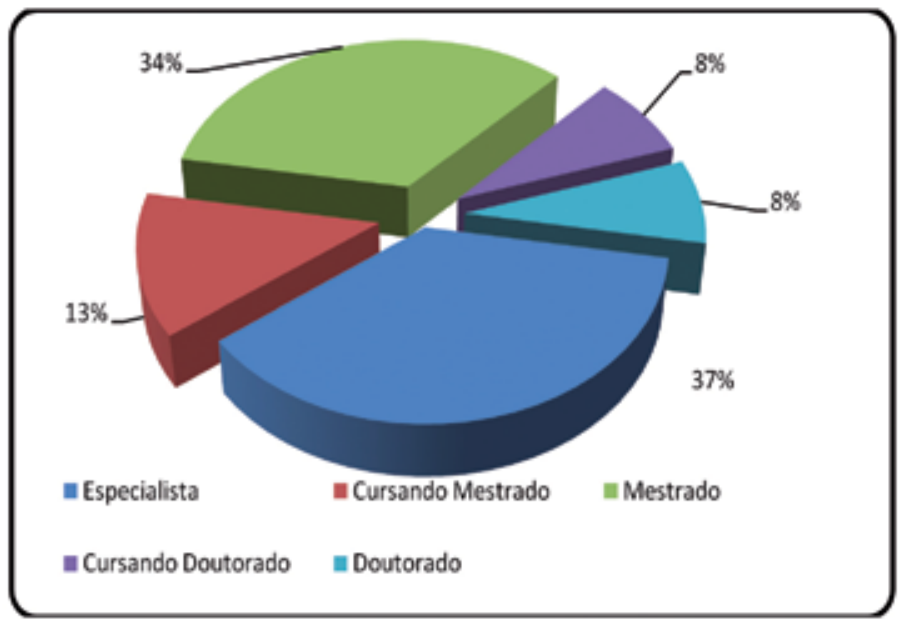

Fonte: Dados da Pesquisa

Os dados acima expostos nos mostram que o quadro docente do curso é qualificado com $34 \%$ de mestres, mas que ainda é necessário incentivar a qualificação contínua dos docentes, assim como é sugerido no PDI da instituição.

Figura 6 - Horas de trabalho semanal na UNESC

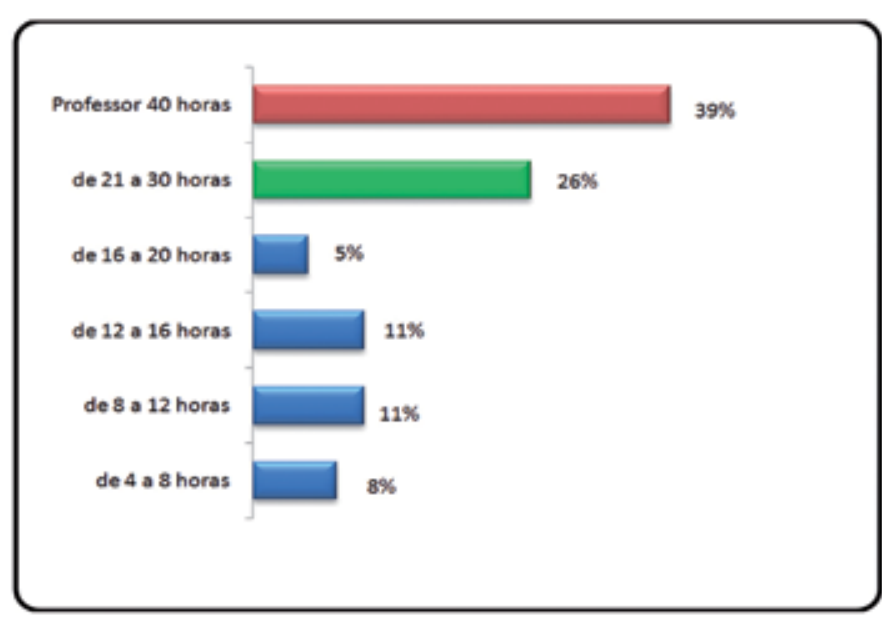

Fonte: Dados da Pesquisa

De acordo com o PDI da UNESC os professores que possuem tempo integral: "é enquadrado neste regime o docente contratado para cumprir uma carga horária de quarenta horas semanais, distribuídas nas atividades de ensino, pesquisa, extensão e administração universitária". (UNIVERSIDADE DO EXTREMO SUL CATARINENSE, 2009, p. 141). Conforme dados apresentados pela pesquisa, o curso de Administração possui $39 \%$ do seu corpo docente com 40 horas semanais, podendo atender as atividades indicadas pelo PDI. 
Figura 7 - Trabalho em outras instituições

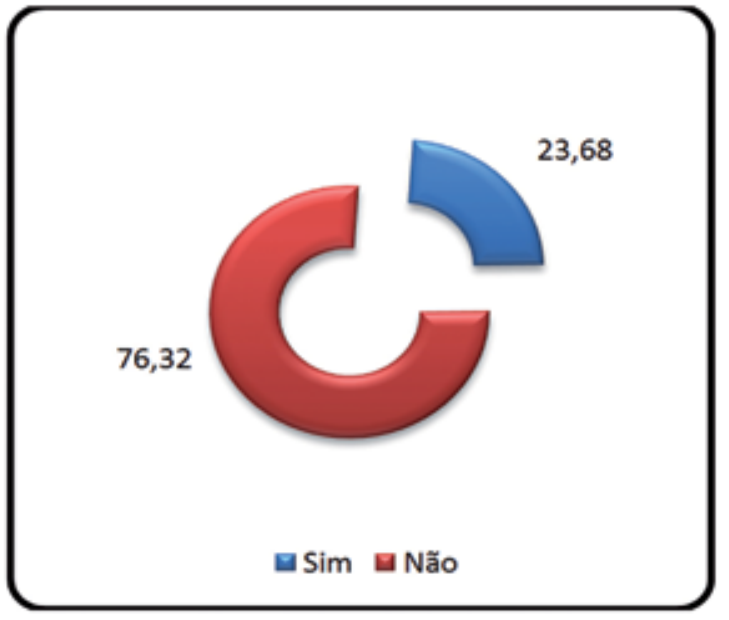

Fonte: Dados da Pesquisa
Figura 8 - Horas de trabalho maior ou menor de ensino além da UNESC

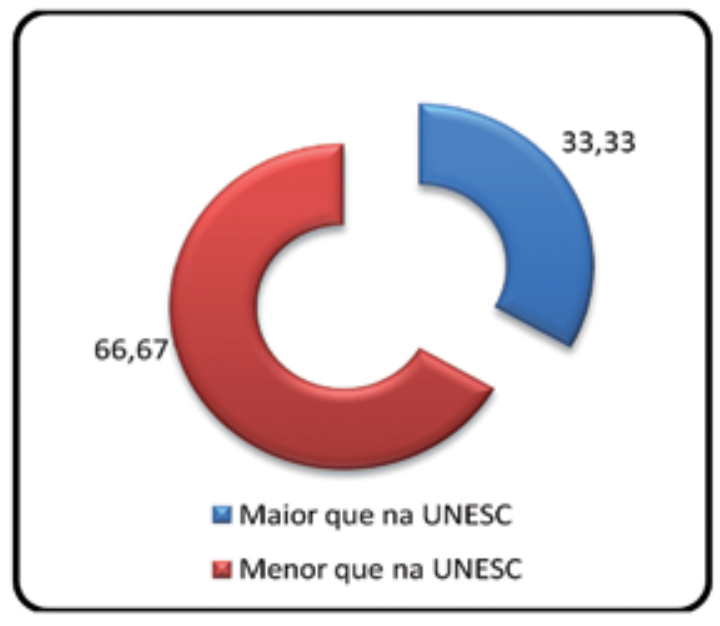

Fonte: Dados da Pesquisa

Como nos mostra os dados acima, o curso possui docentes que trabalham concomitante em outras instituições de ensino. Uma sugestão seria convidar estes docentes para socializar as "boas práticas" ou experiências positivas das demais instituições.

Figura 9 - Outras atividades além da docência e sua carga horária

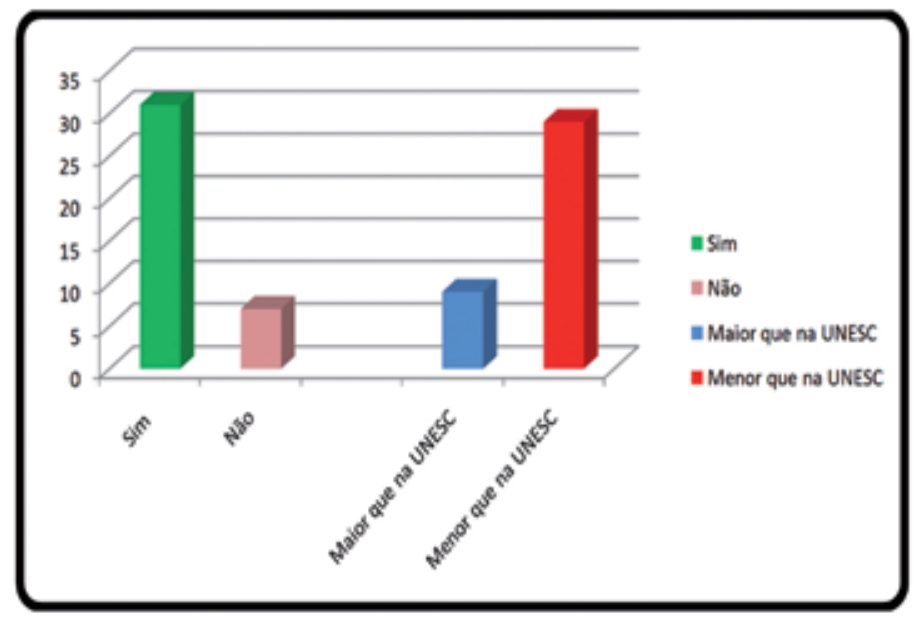

Fonte: Dados da Pesquisa

A pesquisa nos mostra que $81 \%$ dos docentes exercem outras profissões além da docência, este dado pode ser considerado positivo, pois demonstra que os mesmos têm condições de aliar prática e teoria. 
Figura 10 - Exercício da docência como complemento de renda

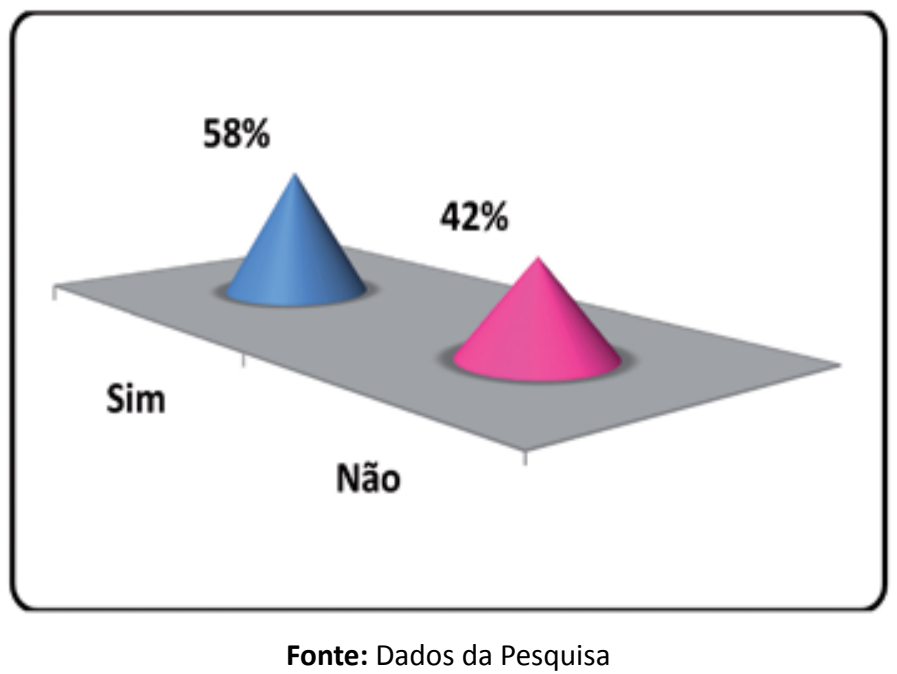

Como mostra o gráfico anterior, a maioria dos docentes exerce outras profissões além da docência e afirmaram que a docência é um complemento de renda, sendo assim, conforme mostra o PDI da instituição se faz importante a valorização docente, "Representada por: a) Incentivo à qualificação, por meio de programas de formação continuada. b) Aproveitamento dos docentes do quadro da UNESC em disciplinas dos programas de pós-graduação e em programas de pesquisa e extensão. c) Aperfeiçoamento permanente do processo seletivo para docentes. d) Incentivo à efetivação do docente no Plano de Carreira. e) Aperfeiçoamento constante do Plano de Carreira.

Figura 11 - Satisfação com as condições de trabalho

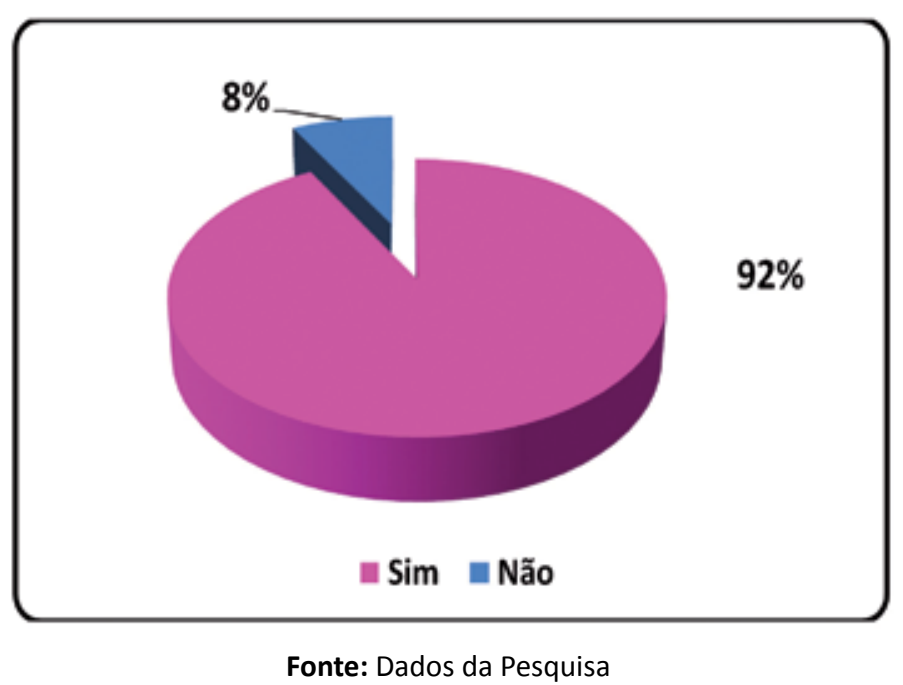

Este é um dado de extrema relevância para a instituição, bem como para o curso, pois mostra que seu corpo docente está plenamente satisfeito com as condições de trabalho oferecidas pela instituição. 


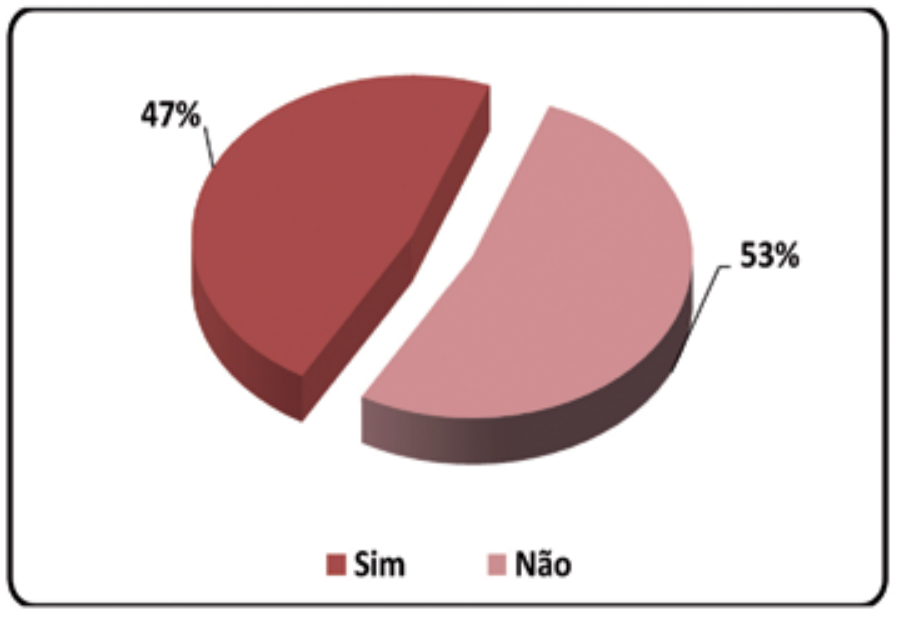

Fonte: Dados da Pesquisa

Dentre os docentes (47\% dos entrevistados) apontaram sugestões de mudanças. As sugestões que aparecem com maior freqüência são: Ambiente climatizado, data show em todas as salas, internet wirelles no bloco R, manutenção permanente dos equipamentos e palestras sobre nutrição. Analisando o PDI da Instituição, observa-se que os itens apontados pelos docentes já são prioridade no planejamento da instituição. Quanto à palestra sobre nutrição, a UNESC oferece na Clinica da Saúde, profissionais para este fim, assim, caberia informar aos docentes sobre os serviços prestados pela mesma.

Figura 13 - Atividades da docência apontadas como estressantes, por vários docentes

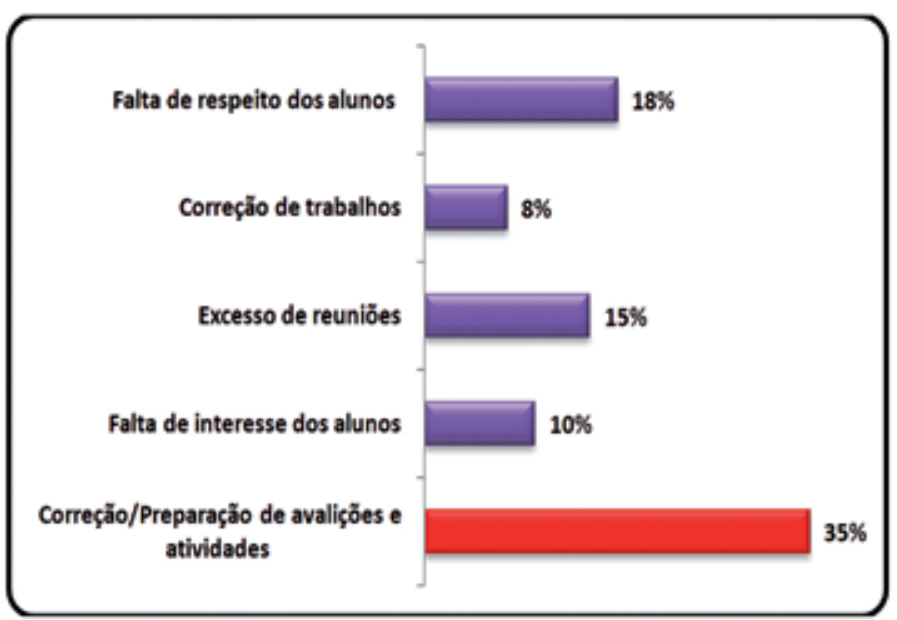

Fonte: Dados da Pesquisa

As atividades apontadas na tabela apareceram com menor freqüência, porem, entendese ser interessante demonstrá-las, pois a maioria delas consta como atribuições do corpo docente (Regimento da UNESC) conforme apresentado na fundamentação teórica. 
Os itens apresentados na figura demonstram as atividades enfatizadas por vários docentes (conforme apresentação). Dois itens precisam ser discutidos e repensados pelo colegiado do curso, que são: Falta de respeito e interesse dos alunos, para que se possam organizar algumas ações que minimizem estes problemas.

Figura 14 - Você se sente estressado?

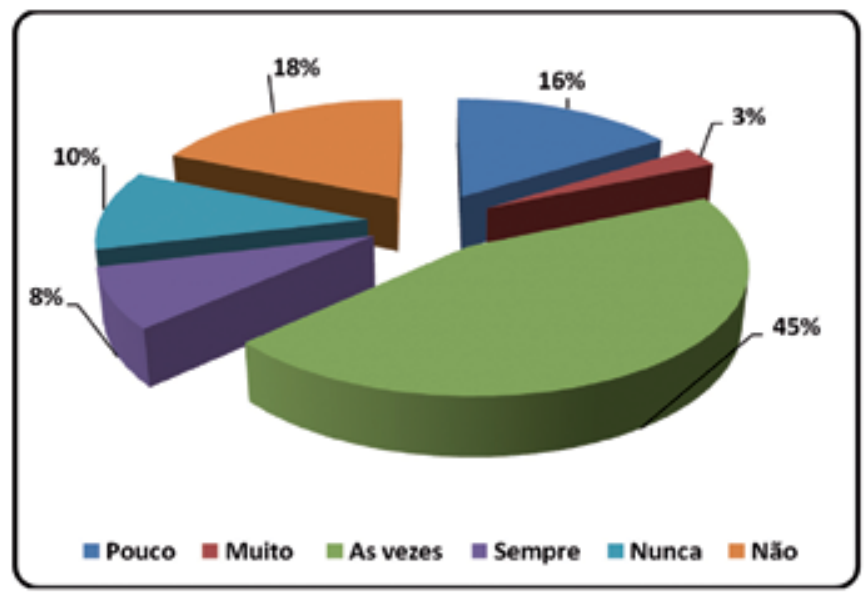

Fonte: Dados da Pesquisa

Este é um dado que precisa ser analisado com atenção pela instituição, pois ainda é apresentado sintomas de estresse somente "às vezes". Seria interessante apresentar aos docentes o Programa Qualidade de Vida, que tem como objetivo "A melhoria das relações interpessoais é um dos objetivos do Programa Qualidade de Vida, vinculado à Diretoria de Desenvolvimento Humano. São realizadas várias atividades, envolvendo acadêmicos, professores e funcionários: yoga (aberto à comunidade externa), yoga para gestantes, palestras, saídas de campo, ginástica laboral, oficinas de artesanato e atividades de harmonização em vários eventos, entre outros."

Figura 15 - Sintomas sentidos pelo docente

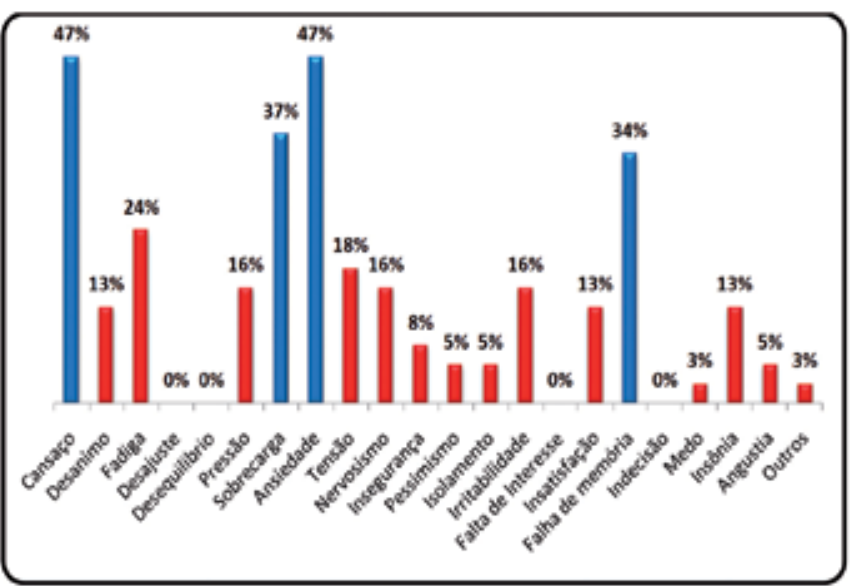

Fonte: Dados da Pesquisa 
Conforme apresentado na fundamentação teórica, a docência exige uma carga extra de trabalho além da sala de aula, bem como, outras atividades pedagógicas. Acreditase que outro fator que está desencadeando estes sintomas, seja o fato dos docentes desenvolverem outras atividades além da docência.

Tabela1 - Número que considera compatível com suas expectativas e vivências

\begin{tabular}{|c|c|c|c|c|c|}
\hline & ESCALA DE GRADUAÇÃO & 1 & 2 & 3 & 4 \\
\hline N. & Como você se sente em relaçào á: & $\begin{array}{l}\text { Muito } \\
\text { insatisfeito }\end{array}$ & Insatisfeito & Satisfeito & $\begin{array}{c}\text { Muito } \\
\text { Satisfeito }\end{array}$ \\
\hline 1 & $\begin{array}{l}\text { Salário justo quando comparado as } \\
\text { funções e atividades que desempenha }\end{array}$ & 2 & 8 & 19 & 7 \\
\hline 2 & $\begin{array}{l}\text { Salário justo quando comparado a } \\
\text { outras instituições }\end{array}$ & 1 & 5 & 23 & 9 \\
\hline 3 & $\begin{array}{l}\text { Quantidade de atividades sob sua } \\
\text { responsabilidade }\end{array}$ & 0 & 4 & 22 & 10 \\
\hline 4 & $\begin{array}{l}\text { Condições ambientais de trabalho } \\
\text { (iluminação, higiene, ventilação e } \\
\text { organização) }\end{array}$ & 0 & 2 & 21 & 13 \\
\hline 5 & $\begin{array}{l}\text { Jornada de trabalho dentro da } \\
\text { Instituição (UNESC) }\end{array}$ & 0 & 3 & 21 & 12 \\
\hline 6 & $\begin{array}{l}\text { Jornada de trabalho fora da } \\
\text { Instituição (UNESC) }\end{array}$ & 0 & 5 & 20 & 6 \\
\hline 7 & $\begin{array}{l}\text { Autonomia em relação ao trabalho } \\
\text { desempenhado }\end{array}$ & 1 & 1 & 18 & 16 \\
\hline 8 & $\begin{array}{l}\text { Informação sobre o processo total de } \\
\text { trabalho }\end{array}$ & 2 & 6 & 22 & 6 \\
\hline 9 & $\begin{array}{l}\text { Disponibilidade de equipamentos } \\
\text { adequados para desenvolver suas } \\
\text { atividades }\end{array}$ & 1 & 5 & 21 & 9 \\
\hline 10 & $\begin{array}{l}\text { Possibilidade de crescimento } \\
\text { profissional }\end{array}$ & 1 & 7 & 19 & 9 \\
\hline 11 & $\begin{array}{l}\text { Segurança e instabilidade no emprego } \\
\text { (na UNESC) }\end{array}$ & 0 & 8 & 24 & 4 \\
\hline 12 & $\begin{array}{l}\text { Incentivos e investimentos da } \\
\text { instituição na capacitação profissional }\end{array}$ & 1 & 9 & 24 & 2 \\
\hline
\end{tabular}




\begin{tabular}{|c|c|c|c|c|c|}
\hline 13 & $\begin{array}{l}\text { Reconhecimento do seu trabalho pela } \\
\text { instituição }\end{array}$ & 2 & 8 & 15 & 11 \\
\hline 14 & $\begin{array}{l}\text { Relacionamento com os diversos } \\
\text { profissionais da instituição }\end{array}$ & 1 & 0 & 21 & 14 \\
\hline 15 & $\begin{array}{l}\text { Garantia e respeito pelos direitos } \\
\text { trabalhistas }\end{array}$ & 0 & 0 & 19 & 17 \\
\hline 16 & Respeito a privacidade a vida pessoal & 1 & 1 & 17 & 17 \\
\hline 17 & $\begin{array}{l}\text { Liberdade de manifestação, } \\
\text { discordância e sugestão }\end{array}$ & 1 & 3 & 23 & 9 \\
\hline 18 & $\begin{array}{l}\text { Equilíbrio entre os horários de } \\
\text { trabalho, exigências pessoais e } \\
\text { familiares }\end{array}$ & 3 & 8 & 20 & 5 \\
\hline 19 & $\begin{array}{l}\text { Realização de atividades esportivas } \\
\text { no tempo livre }\end{array}$ & 7 & 17 & 8 & 3 \\
\hline 20 & $\begin{array}{l}\text { Tempo para lazer com a família e com } \\
\text { os amigos }\end{array}$ & 0 & 15 & 17 & 4 \\
\hline 21 & Responsabilidade social da UNESC & 0 & 6 & 20 & 9 \\
\hline 22 & $\begin{array}{l}\text { Imagem da UNESC no cenário local e } \\
\text { regional }\end{array}$ & 0 & 2 & 15 & 19 \\
\hline 23 & $\begin{array}{l}\text { Realização pessoal pelo trabalho } \\
\text { desenvolvido }\end{array}$ & 0 & 1 & 16 & 19 \\
\hline
\end{tabular}

Fonte: Dados da Pesquisa

\section{CONCLUSÃO}

O presente estudo trouxe para os pesquisadores uma experiência riquíssima, porque proporcionou conhecer melhor o cotidiano dos professores que exercem a docência no Curso de Administração da UNESC, bem como identificar suas expectativas, lembrando que o temas deste estudo foi conhecer a visão dos professores do Curso de Administração da UNESC sobre a sua qualidade de vida no trabalho.

Em relação aos objetivos apresentados, entende-se que todos foram alcançados, identificou-se o perfil dos professores do Curso, onde constatou-se que, o corpo docente é composto em sua maioria por professores do sexo masculino, casados e com idade entre 40 e 50 anos. Outro fator relevante foi em relação à titulação do corpo docente, que é composto em maioria por mestres, e possui 03 Doutores e 02 doutorandos, fator que fortalece o curso, bem como a instituição. 
Quanto a percepção dos professores acerca da docência e do ambiente de trabalho, o estudo mostrou que os mesmos estão satisfeitos com o curso e com a UNESC.

No questionário aplicado, havia uma pergunta que procurava detectar se os professores apresentavam características da síndrome de Burnout, e dos 38 docentes pesquisados nenhum apresentou os sintomas.

Os Docentes pesquisados apontaram propostas de melhoria no ambiente de trabalho para melhorar a qualidade de vida, dentre elas destaca-se: Ambiente climatizado, data show em todas as salas, internet wirelles no bloco $\mathrm{R}$, manutenção permanente dos equipamentos e palestras sobre nutrição, é importante salientar que estes itens também são ressaltados no PDI da instituição como ações prioritárias.

No que tange ao trabalho docente apontado como estressante, o item com maior destaque é sobre a correção de avaliações e trabalhos. A UNESC possui documento que trata especificamente da avaliação do desempenho acadêmico, o Regimento Geral da UNESC, Resolução n. 01/2007/CSA, artigo 86, estabelece que: "A avaliação do processo de ensino-aprendizagem, co-responsabilidade de todos os sujeitos envolvidos, estará fundamentada no Projeto Político Pedagógico institucional e será processual, com preponderância dos aspectos qualitativos sobre os quantitativos".

Por processualidade do desempenho acadêmico, entende-se uma concepção de avaliação integrada ao processo de ensino-aprendizagem, objetivando o acompanhamento do desempenho do acadêmico e do professor.

Comprometimento com uma gestão pedagógica democrática e participativa. A gestão pedagógica materializada no espaço da sala de aula deve pautar-se no respeito às diferenças individuais, na liberdade de expressão política, filosófica, cultural e religiosa e no diálogo permanente entre professor, estudante e coordenação.

No geral, a pesquisa mostrou que os docentes estão satisfeitos com o curso e com a maneira que a instituição vem conduzindo o processo de gestão.

\title{
QUANTITATIVE STUDY OF THE PERCEPTION OF QUALITY OF LIFE IN THE WORKPLACE IN VIEW OF TEACHERS IN COURSE OF ADMINISTRATION OF UNESC.
}

\begin{abstract}
The world of the work comes passing for transformations that affect the collaborators and the society, also the university professors. In this direction, the subject quality of life in the work comes conquering relevance in the social scene, therefore to globe the expectations, styles and projects of life of the people and the collective, when they involve its environment of work. Being thus, this research, that had as objective to characterize and to analyze the aspects of the style and the quality of life of professors of superior education, specifically in the Course of Administration of the UNESC was become
\end{abstract}


fullfilled. The undertaken method of inquiry was of quantitative nature of bibliographical matrix. Scientific, dissertações of mestrado and teses had been had access of doutorado, published articles in the computer science data bases. One searched, also, literatures in the quantity of the library of the University of the South Extremity Catarinense - UNESC. The study it was classified as of field, to explore and description, being developed through quantitative procedures of collection and analysis of the data, by means of a composed questionnaire for 15 closed questions. The participants had been the professors of the course in study, totalizing 41 searched, of which, 38 had answered questionnaire, totalizing $93 \%$ of the sample. The results had pointed that the professors perceive the quality of life in the work of positive form, they are satisfied with the work environment, and trust the institution which is tied.

Keywords: Institutions of Education. Professors of University Education. Quality of life in the work. Syndrome of Burnout.

\section{REFERÊNCIAS}

APPOLINÁRIO, Fábio. Dicionário da Metodologia Científica: Um guia para a Produção do Conhecimento Cientifico. São Paulo: Atlas, 2004.

CARLOTTO. Mary Sandra. A Síndrome de Burnout e o Trabalho Docente. Psicologia em Estudo, Maringá, v. 7, n. 1, p. 21-29, jan./jun. 2002

CHIZZOTTI, Antonio. Pesquisa em ciências humanas e sociais. 7. ed. São Paulo: Cortez, 2005.

CODO, W. (coord) Educação: carinho e trabalho. Rio de Janeiro: Vozes, 1999.

MACHADO, Rosane do Carmo. 0 ambiente Ergonômico em Instituição de Ensino Superior e seu Reflexo na Atividade Docente e na Qualidade de Vida na Organização. Tese de Doutorado. Universidade Federal de Santa Catarina - UFSC. Departamento de Engenharia de Produção. Florianópolis, 2009.

MARCONI, Marina de Andrade; LAKATOS, Eva Maria. Técnicas de pesquisa: planejamento e execução de pesquisas, amostragens e técnicas de pesquisa, elaboração, análise e interpretação de dados. 5. ed São Paulo: Atlas, 2002.

MAZZOTTA, M.J.S. Trabalho docente e formação de professores de educação especial. São Paulo: EPU, 1998.

MENDES, F. M. P. Incidência de burnout em professores universitários. Florianópolis, 2002. Dissertação (Mestrado em Engenharia de Produção) - Programa de PósGraduação em Engenharia de Produção, Universidade Federal de Santa Catarina. 
OLIVEIRA, Jayr Figueiredo de. Metodologia para desenvolvimento de projetos de sistemas: guia prático/ Jayr Figueiredo de Oliveira. 3.ed. rev. e ampl. São Paulo: Érica, 1999.

ORGANIZAÇÃO MUNDIAL DA SAÚDE (OMS). Guia para a boa prescrição médica. Porto Alegre: Artmed, 1998. 124 p.

RODRIGUES, M.V.C.; AMORIM, T. Uma investigação da qualidade de vida nas organizações brasileiras. In: Revista Brasileira de Administração Contemporânea, AMPAD, Vol. I, nr. 9, setembro/1995, p. 261-285.

UNIVERSIDADE DO EXTREMO SUL CATARINENSE. Plano de Carreira Docente. Criciúma: UNESC, 2007.

UNIVERSIDADE DO EXTREMO SUL CATARINENSE. Recava - Reconhecimento e Avaliação de Cursos. Criciúma: UNESC, 2008.

UNIVERSIDADE DO EXTREMO SUL CATARINENSE. Plano de Desenvolvimento Institucional (PDI). Criciúma: UNESC, 2009.

VERGARA, Sylvia Constant. Projetos e Relatórios de Pesquisa em Administração. 11. ed. São Paulo: Atlas, 2009.

VIANNA, Ilca Oliveira de Almeida. Metodologia do trabalho científico: um enfoque didático da produção científica. São Paulo: EPU, 2001.

VIEIRA, JULIANE PEDRINI. SÍNDROME DE BURNOUT EM DOCENTES: UM ESTUDO EXPLORATÓRIO. 2008. 45 F. MONOGRAFIA (CURSO DE PSICOLOGIA) - UNIVERSIDADE DO EXTREMO SUL CATARINENSE - UNESC, CRICIÚMA, 2008.

\section{SOBRE OS AUTORES}

\begin{tabular}{|c|c|}
\hline $\begin{array}{c}\text { Rosane } \\
\text { Deoclésia } \\
\text { Aléssio Dal Toé }\end{array}$ & $\begin{array}{l}\text { Possui graduação em Pedagogia pela Universidade do Extremo Sul Catarinense- } \\
\text { UNESC (1993), Especialização em fundamentos Psicopedagógicos do Ensino, } \\
\text { pela Universidade do Extremo Sul Catarinense-UNESC(2000), Especialização } \\
\text { em gestão Escolar pela Universidade do Estado de Santa Catarina-UDESC(2002), } \\
\text { Especialização em Gestão Empresarial pela Universidade do Extremo Sul } \\
\text { Catarinense-UNESC(2009), . Mestre em Educação e Cultura pela Universidade } \\
\text { do Estado de Santa Catarina-UDESC (2005). Doutoranda em Gestão do } \\
\text { Conhecimento no Programa de Pós Graduação de Engenharia e Gestão do } \\
\text { Conhecimento da Universidade Federal de Santa Catarina - UFSC. Atualmente } \\
\text { é professora dos Cursos de Graduação e Pós Graduação da Universidade do } \\
\text { Extremo Sul Catarinense-UNESC e dos Cursos de Pós Graduação do SENAl } \\
\text { Florianópolis/SC. }\end{array}$ \\
\hline
\end{tabular}




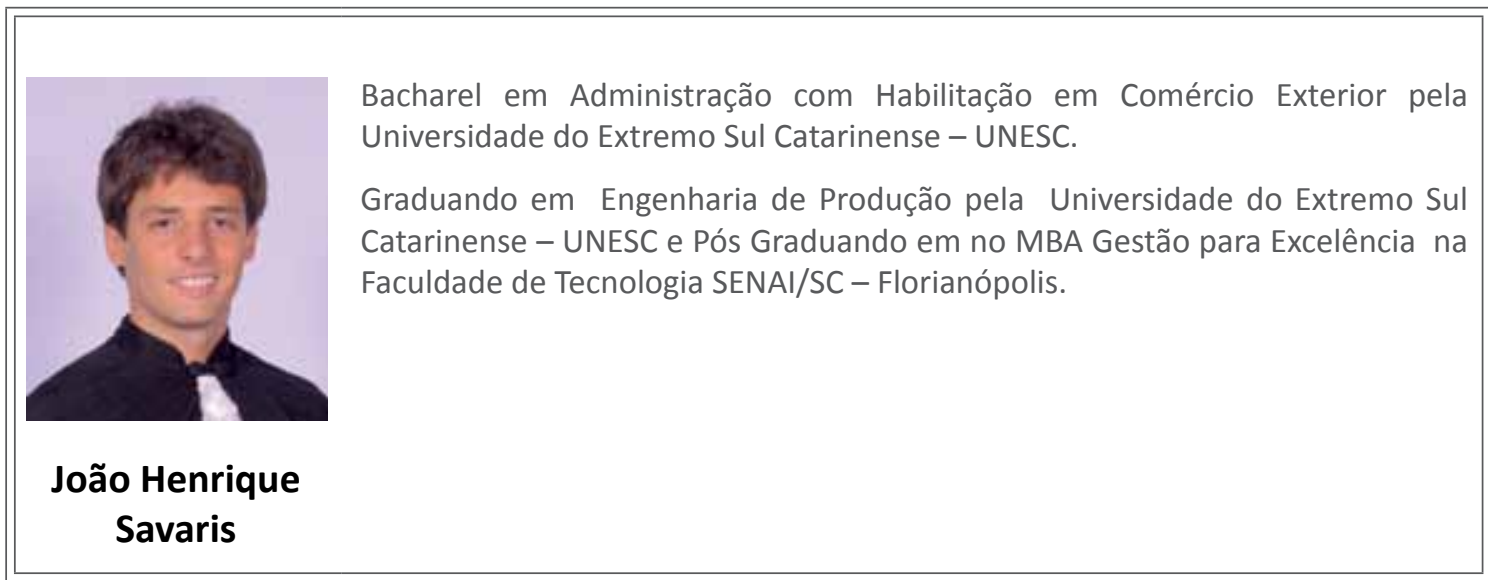

Bacharel em Administração de Empresas e Direito pela Universidade do
Sul Catarinense - UNISUL. Especialista em Administração de Empresas;
Administração de Recursos Humanos e Educação Superior. Mestre em
Engenharia de Produção pela Universidade Federal de Santa Catarina - UFSC.
Professor titular da Universidade do Extremo Sul Catarinense - UNESC.
Roberto
Dagostin

